\title{
Price competition in the Hotelling model with uncertainty on costs
}

\section{Alberto A. Pinto \& Telmo Parreira}

To cite this article: Alberto A. Pinto \& Telmo Parreira (2015) Price competition in the Hotelling model with uncertainty on costs, Optimization, 64:11, 2477-2493, DOI: 10.1080/02331934.2014.917304

To link to this article: https://doi.org/10.1080/02331934.2014.917304

曲 Published online: 15 May 2014.

Submit your article to this journal $\pi$

III Article views: 264

Q View related articles $₫$

View Crossmark data $\nearrow$

4 Citing articles: 2 View citing articles 진 


\title{
Price competition in the Hotelling model with uncertainty on costs
}

\author{
Alberto A. Pinto ${ }^{\text {ac* }}$ and Telmo Parreira ${ }^{\text {bc }}$ \\ ${ }^{a}$ Faculty of Sciences, Department of Mathematics, University of Porto, Porto, Portugal; \\ ${ }^{b}$ Department of Mathematics and Applications, University of Minho, Braga, Portugal; \\ ${ }^{c}$ LIAAD-INESC, Porto, Portugal
}

(Received 13 August 2013; accepted 2 April 2014)

\begin{abstract}
For the linear Hotelling model with firms located at the boundaries of the segment line, we study the price competition in a scenario of incomplete information in the production costs of both firms. We introduce the bounded uncertain costs (BUC) condition in the production costs and we prove that there is a local optimum price strategy if and only if the BUC condition holds. We compute explicitly the local optimum price strategy and we prove that it does not depend upon the distributions of the production costs of the firms, except on their first moments. We prove that the ex-post profit of a firm is smaller than its ex-ante profit if and only if the production cost of the other firm is greater than its expected cost.
\end{abstract}

Keywords: Hotelling model; price competition; duopoly; uncertainty

AMS Subject Classifications: 91B24; 91B38; 91B44

\section{Introduction}

Since the seminal work of Hotelling,[1] the model of spatial competition has been seen by many researchers as an attractive framework for analysing oligopoly markets (see [2-9]).

In his model, Hotelling presents a city represented by a line segment where a uniformly distributed continuum of consumers have to buy a homogeneous good. Consumers have to support linear transportation costs when buying the good in one of the two firms of the city. The firms compete in a two-staged location-price game, where simultaneously choose their location and afterwards set their prices in order to maximize their profits. Hotelling concluded that firms would agglomerate at the centre of the line, an observation referred as the 'Principle of Minimum Differentiation'. In 1979, D'Aspremont et al. [10] showed that the 'Principle of Minimum Differentiation' was invalid, since there was no price equilibrium solution for all possible locations of the firms, in particular when they were not far enough from each other. Moreover, in the same article, D'Aspremont et al. introduce a modification in the Hotelling model, considering quadratic transportation costs instead of linear. The introduction of this feature removed the discontinuities verified in the profit and demand functions, which was a problem in the Hotelling model and they show that, under quadratic transportation costs, a price equilibrium exists for all locations and a location equilibrium

*Corresponding author. Email: aapinto@fc.up.pt 
exists and involves maximum product differentiation, i.e. the firms opt to locate at the extremes of the line.

Hotelling and D'Aspremont et al. consider that the production costs of both firms are equal to zero. Ziss [11] introduce a modification in the model of D'Aspremont et al. by allowing for different production costs between the two firms and examines the effect of heterogeneous production technologies on the location problem. Ziss shows that a price equilibrium exists for all locations and concludes that when the difference between the production costs is small, a price and location equilibrium exists in which the firms prefer to locate in different extremes of the line. However, if the difference between the production costs is sufficiently large, a location equilibrium does not exist.

Using linear transportation costs, Boyer et al. [12] study the case where the firms choose sequentially their location and then compete in delivered prices (see [13]), assuming that the first mover has perfect information, while the second mover does not know if the opponent firm has a low or high production cost. Using quadratic transportation costs, a similar model but under mill pricing setting was studied by Boyer et al. [14] and by Biscaia and Sarmento [15] in the case where firms simultaneously choose their locations. However, Boyer et al. [14] and Biscaia and Sarmento [15] consider that the uncertainty on the productions costs exists only during the first subgame in location strategies. Then the production costs are revealed to the firms before the firms have to choose their optimal price strategies and so the second subgame has complete information.

In this work, we do not study the Hotelling models in which the location choice by the firms plays a major rule, but models where the location of firms are fixed, that is, models of price competition under spatial nature. We assume that the firms are located at the extremes of the line and so we do not study the first subgame in location strategies. Our main goal is to study the price formation in the second subgame with incomplete information in the production costs of both firms. The incomplete information consists in each firm of knowing its production cost but being uncertain about the competitor cost as usual in oligopoly theory (see [16-25]). We show that the first and second moments of probability distribution in the production costs are the only relevant information for price formation and all other relevant economic quantities.

We introduce the definition of local optimum price strategy that is characterized by a local optimum property and by a duopoly property. We say that a price strategy for both firms is a local optimum price strategy if (i) any small deviation of a price of a firm provokes a decrease in its own ex-ante profit (local optimum property); and (ii) both firms have nonempty market for every pair of production costs (duopoly property). A relevant property of the local optimum price strategy is that a Nash price equilibrium satisfying the duopoly property has to be a local optimum price strategy.

We introduce the bounded uncertain costs BUC condition that defines a bound for the production costs in terms only of the exogenous variables that are the transportation cost and the road length of the segment line (see Section 4). Hence, the prices strategies do not appear in the BUC condition. We prove that the second subgame has a local optimum price strategy if and only if the BUC condition holds. Under the bounded costs BUC condition, we prove that the local optimum price strategy for the firms is unique. Furthermore, we compute explicitly the formula for the local optimum strategic price strategy that is simple and leaves clear the influence of the relevance economic exogenous quantities in the price formation. In particular, we observe that the local optimum price strategy does not depend on the distributions of the production costs of the firms, except on their first moment. We 


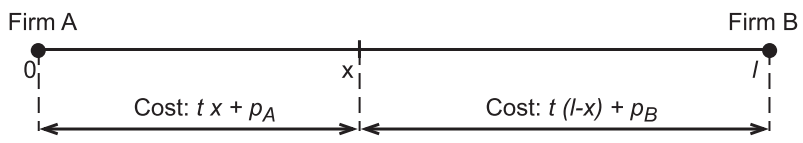

Figure 1. Hotelling's linear city.

note that the novelty and elegance of the proof consists in computing explicitly the expected prices of the optimal strategies before computing the optimal strategies.

We explicitly compare the ex-ante and ex-post profits, consumer surplus and welfare. We prove that, under specific bounded costs conditions, the ex-post profit of a firm is smaller than its ex-ante profit if and only if the production cost of the other firm is greater than its expected cost (see Equations (22) and (21)).

Our techniques allowed the results to be universal in the incomplete information scenario because they apply to all probability distributions in the production costs.

\section{Hotelling model under complete information}

The buyers of a commodity will be supposed uniformly distributed along a line with length $l$. At the two ends of the line, there are two firms $A$ and $B$ located at positions 0 and $l$, respectively, selling the same commodity with unitary production $\operatorname{costs} c_{A}$ and $c_{B}$. No customer has any preference for either seller except on the ground of price plus transportation cost $t$. We will assume that each consumer buys a single unit of the commodity, in each unit of time and in each unit of length of the line. Denote A's price by $p_{A}$ and B's price by $p_{B}$. The point of division $\left.x=x\left(p_{A}, p_{B}\right) \in\right] 0, l[$ between the regions served by the two entrepreneurs is determined by the condition that at this place, it is a matter of indifference whether one buys from $A$ or from $B$ (see Figure 1).

The point $x$ is the location of the indifferent consumer to buy from firm $A$ or firm $B$, if

$$
p_{A}+t x=p_{B}+t(l-x) .
$$

Solving for $x$, we obtain

$$
x=\frac{p_{B}-p_{A}+t l}{2 t} .
$$

Both firms have a non-empty market share if and only if $x \in] 0, l[$. Hence, both firms have a non-empty market share if and only if the prices satisfy

$$
\left|p_{A}-p_{B}\right|<t l \text {. }
$$

Assuming inequality (1), both firms $A$ and $B$ have a non-empty demand ( $x$ and $l-x$ ) and the profits of the two firms are defined, respectively, by

$$
\pi_{A}=\left(p_{A}-c_{A}\right) x=\left(p_{A}-c_{A}\right) \frac{p_{B}-p_{A}+t l}{2 t} ;
$$

and

$$
\pi_{B}=\left(p_{B}-c_{B}\right)(l-x)=\left(p_{B}-c_{B}\right) \frac{p_{A}-p_{B}+t l}{2 t} .
$$

Two of the fundamental economic quantities in oligopoly theory are the consumer surplus $C S$ and the welfare $W$. The consumer surplus is the gain of the consumers community 
for given price strategies of both firms. The welfare is the gain of the state that includes the gains of the consumers community and the gains of the firms for given price strategies of both firms.

Let us denote by $v_{T}$ be the total amount that consumers are willing to pay for the commodity. The total amount $v(y)$ that a consumer located at $y$ pays for the commodity is given by

$$
v(y)= \begin{cases}p_{A}+t y & \text { if } 0<y<x \\ p_{B}+t(l-y) & \text { if } x<y<l\end{cases}
$$

The consumer surplus CS is the difference between the total amount that a consumer is willing to pay $v_{T}$ and the total amount that the consumer pays $v(y)$

$$
C S=\int_{0}^{l}\left(v_{T}-v(y)\right) \mathrm{d} y .
$$

The welfare $W$ is given by adding the profits of firms $A$ and $B$ with the consumer surplus

$$
W=C S+\pi_{A}+\pi_{B} .
$$

Definition 2.1 A price strategy $\left(\underline{p}_{A}, \underline{p}_{B}\right)$ for both firms is a local optimum price strategy if (i) for every small deviation of the price $\underline{p}_{A}$, the profit $\pi_{A}$ of firm $A$ decreases, and for every small deviation of the price $\underline{p}_{B}$, the profit $\pi_{B}$ of firm $B$ decreases (local optimum property); and (ii) the indifferent consumer exists, i.e. $0<\underline{x}<l$ (duopoly property).

Let us compute the local optimum price strategy $\left(\underline{p}_{A}, \underline{p}_{B}\right)$. Differentiating $\pi_{A}$ with respect to $p_{A}$ and $\pi_{B}$ with respect to $p_{B}$ and equalizing to zero, we obtain the first-order conditions (FOC). The FOC implies that

$$
\underline{p}_{A}=t l+\frac{1}{3}\left(2 c_{A}+c_{B}\right)
$$

and

$$
\underline{p}_{B}=t l+\frac{1}{3}\left(c_{A}+2 c_{B}\right) .
$$

We note that the first-order conditions refer to jointly optimizing the profit function (2) with respect to the price $p_{A}$ and the profit function (3) with respect to the price $p_{B}$.

Since the profit functions (2) and (3) are concave, the second-order conditions for this maximization problem are satisfied and so the prices (6) and (7) are indeed maxima for the functions (2) and (3), respectively. The corresponding equilibrium profits are given by

$$
\underline{\pi}_{A}=\frac{\left(3 t l+c_{B}-c_{A}\right)^{2}}{18 t}
$$

and

$$
\underline{\pi}_{B}=\frac{\left(3 t l+c_{A}-c_{B}\right)^{2}}{18 t} .
$$

Furthermore, the consumer indifference location corresponding to the maximizers $\underline{p}_{A}$ and $\underline{p}_{B}$ of the profit functions $\pi_{A}$ and $\pi_{B}$ is

$$
\underline{x}=\frac{l}{2}+\frac{c_{B}-c_{A}}{6 t} .
$$


Finally, for the pair of prices $\left(\underline{p}_{A}, \underline{p}_{B}\right)$ to be a local optimum price strategy, we need assumption (1) to be satisfied with respect to these pair of prices. We observe that assumption (1) is satisfied with respect to the pair of prices $\left(\underline{p}_{A}, \underline{p}_{B}\right)$ if and only if the following condition with respect to the production costs is satisfied.

Definition 2.2 The Hotelling model satisfies the bounded costs $(B C)$ condition, if

$$
\left|c_{A}-c_{B}\right|<3 t l .
$$

We note that under the $\mathrm{BC}$ condition, the prices are higher than the production costs $\underline{p}_{A}>c_{A}$ and $\underline{p}_{B}>c_{B}$. Hence, there is a local optimum price strategy if and only if the $\overline{\mathrm{B}} \mathrm{C}$ condition holds. Furthermore, under the $\mathrm{BC}$ condition, the pair of prices $\left(\underline{p}_{A}, \underline{p}_{B}\right)$ is the local optimum price strategy.

By Equation (4), the consumer surplus $\underline{C S}$ with respect to the local optimum price strategy $\left(\underline{p}_{A}, \underline{p}_{B}\right)$ is given by

$$
\underline{C S}=\int_{0}^{l}\left(v_{T}-v(x)\right) \mathrm{d} x=v_{T} l-\frac{3}{2} t l^{2}-\frac{c_{A}+2 c_{B}}{3} l+\frac{\left(c_{B}-c_{A}+3 t l\right)^{2}}{36 t} .
$$

By Equation (5), the welfare $\underline{W}$ is given by

$$
\underline{W}=v_{T} l-\frac{1}{4} t l^{2}-\frac{c_{A}+c_{B}}{2} l+\frac{5\left(c_{A}-c_{B}\right)^{2}}{36 t} .
$$

\section{Incomplete information on the production costs}

The incomplete information consists in each firm to know its production cost but to be uncertain about the competitor cost. In this section, we introduce a simple notation that is fundamental for the elegance and understanding of the results presented in this paper.

Let the triples $\left(I_{A}, \Omega_{A}, q_{A}\right)$ and $\left(I_{B}, \Omega_{B}, q_{B}\right)$ represent (finite, countable or uncountable) sets of types $I_{A}$ and $I_{B}$ with $\sigma$-algebras $\Omega_{A}$ and $\Omega_{B}$ and probability measures $q_{A}$ and $q_{B}$, over $I_{A}$ and $I_{B}$, respectively.

We define the expected values $E_{A}(f), E_{B}(f)$ and $E(f)$ with respect to the probability measures $q_{A}$ and $q_{B}$ as follows:

$$
E_{A}(f)=\int_{I_{A}} f(z, w) \mathrm{d} q_{A}(z) ; \quad E_{B}(f)=\int_{I_{B}} f(z, w) \mathrm{d} q_{B}(w)
$$

and

$$
E(f)=\int_{I_{A}} \int_{I_{B}} f(z, w) \mathrm{d} q_{B}(w) \mathrm{d} q_{A}(z)
$$

Let $c_{A}: I_{A} \rightarrow \mathbb{R}_{0}^{+}$and $c_{B}: I_{B} \rightarrow \mathbb{R}_{0}^{+}$be measurable functions where $c_{A}^{z}=c_{A}(z)$ denotes the production cost of firm $A$ when the type of firm $A$ is $z \in I_{A}$ and $c_{B}^{w}=c_{B}(w)$ denotes the production cost of firm $B$ when the type of firm $B$ is $w \in I_{B}$. Furthermore, we assume that the expected values of $c_{A}$ and $c_{B}$ are finite

$$
E\left(c_{A}\right)=E_{A}\left(c_{A}\right)=\int_{I_{A}} c_{A}^{z} \mathrm{~d} q_{A}(z)<\infty ; \quad E\left(c_{B}\right)=E_{B}\left(c_{B}\right)=\int_{I_{B}} c_{B}^{w} \mathrm{~d} q_{B}(w)<\infty .
$$


We assume that $\mathrm{d} q_{A}(z)$ denotes the probability of the belief of the firm $B$ on the production costs of the firm $A$ to be $c_{A}^{z}$. Similarly, assume that $\mathrm{d} q_{B}(w)$ denotes the probability of the belief of the firm $A$ on the production costs of the firm $B$ to be $c_{B}^{w}$.

The simplicity of the following cost deviation formulas is crucial to express the main results of this article in a clear and understandable way. The cost deviations of firm $A$ and firm $B$

$$
\Delta_{A}: I_{A} \rightarrow \mathbb{R}_{0}^{+} \text {and } \Delta_{B}: I_{B} \rightarrow \mathbb{R}_{0}^{+}
$$

are given, respectively, by $\Delta_{A}(z)=c_{A}^{z}-E\left(c_{A}\right)$ and $\Delta_{B}(w)=c_{B}^{w}-E\left(c_{B}\right)$. The cost deviation between the firms

$$
\Delta_{C}: I_{A} \times I_{B} \rightarrow \mathbb{R}_{0}^{+}
$$

is given by $\Delta_{C}(z, w)=c_{A}^{z}-c_{B}^{w}$. Since the meaning is clear, we will use through the paper the following simplified notation:

$$
\Delta_{A}=\Delta_{A}(z) ; \quad \Delta_{B}=\Delta_{B}(w) \text { and } \Delta_{C}=\Delta_{C}(z, w) .
$$

The expected cost deviation $\Delta_{E}$ between the firms is given by $\Delta_{E}=E\left(c_{A}\right)-E\left(c_{B}\right)$. Hence,

$$
\Delta_{C}-\Delta_{E}=\Delta_{A}-\Delta_{B}
$$

Let $V_{A}$ and $V_{B}$ be the variances of the production $\operatorname{costs} c_{A}$ and $c_{B}$, respectively. We observe that

$$
E\left(\Delta_{C}\right)=\Delta_{E} ; \quad E\left(\Delta_{A}^{2}\right)=E_{A}\left(\Delta_{A}^{2}\right)=V_{A} ; \quad E\left(\Delta_{B}^{2}\right)=E_{B}\left(\Delta_{B}^{2}\right)=V_{B} .
$$

Furthermore,

$$
\begin{gathered}
E_{A}\left(\Delta_{C}^{2}\right)=\Delta_{B}^{2}+V_{A}+\Delta_{E}\left(\Delta_{E}-2 \Delta_{B}\right) \\
E_{B}\left(\Delta_{C}^{2}\right)=\Delta_{A}^{2}+V_{B}+\Delta_{E}\left(\Delta_{E}+2 \Delta_{A}\right) \\
E\left(\Delta_{C}^{2}\right)=\Delta_{E}^{2}+V_{A}+V_{B}
\end{gathered}
$$

\section{Local optimal price strategy under incomplete information}

In this section, we introduce incomplete information in the classical Hotelling game and we find the local optimal price strategy. We introduce the bounded uncertain costs condition that allows us to find the local optimum price strategy.

A price strategy $\left(p_{A}, p_{B}\right)$ is given by a pair of functions $p_{A}: I_{A} \rightarrow \mathbb{R}_{0}^{+}$and $p_{B}: I_{B} \rightarrow$ $\mathbb{R}_{0}^{+}$, where $p_{A}^{z}=p_{A}(z)$ denotes the price of firm $A$ when the type of firm $A$ is $z \in I_{A}$ and $p_{B}^{w}=p_{B}(w)$ denotes the price of firm $B$ when the type of firm $B$ is $w \in I_{B}$. We note that $E\left(p_{A}\right)=E_{A}\left(p_{A}\right)$ and $E\left(p_{B}\right)=E_{B}\left(p_{B}\right)$. The indifferent consumer $x: I_{A} \times I_{B} \rightarrow(0, l)$ is given by

$$
x^{z, w}=\frac{p_{B}^{w}-p_{A}^{z}+t l}{2 t} .
$$

The ex-post profit of the firms is the effective profit of the firms given a realization of the production costs for both firm. Hence, it is the main economic information for both firms. However, the incomplete information prevents the firms to have access to their ex-post 
profits except after the firms have already decided their price strategies. The ex-post profits $\pi_{A}^{E P}: I_{A} \times I_{B} \rightarrow \mathbb{R}_{0}^{+}$and $\pi_{B}^{E P}: I_{A} \times I_{B} \rightarrow \mathbb{R}_{0}^{+}$are given by

$$
\pi_{A}^{E P}(z, w)=\pi_{A}(z, w)=\left(p_{A}^{z}-c_{A}^{z}\right) x^{z, w}
$$

and

$$
\pi_{B}^{E P}(z, w)=\pi_{B}(z, w)=\left(p_{B}^{w}-c_{B}^{w}\right)\left(l-x^{z, w}\right) .
$$

The ex-ante profit of the firms is the expected profit of the firm that know their production cost but are uncertain about the production cost of the competitor firm. The ex-ante profits $\pi_{A}^{E A}: I_{A} \rightarrow \mathbb{R}_{0}^{+}$and $\pi_{B}^{E A}: I_{B} \rightarrow \mathbb{R}_{0}^{+}$are given by

$$
\pi_{A}^{E A}(z)=E_{B}\left(\pi_{A}^{E P}\right) \text { and } \pi_{B}^{E A}(w)=E_{A}\left(\pi_{B}^{E P}\right) .
$$

We note that the expected profit $E\left(\pi_{A}^{E P}\right)$ of firm $A$ is equal to $E_{A}\left(\pi_{A}^{E A}\right)$ and the expected profit $E\left(\pi_{B}^{E P}\right)$ of firm $B$ is equal to $E_{B}\left(\pi_{B}^{E A}\right)$.

The incomplete information forces the firms to have to choose their price strategies using their knowledge of their ex-ante profits, to which they have access, instead of the ex-post profits, to which they do not have access except after the price strategies are decided.

Definition 4.1 A price strategy $\left(\underline{p}_{A}, \underline{p}_{B}\right)$ for both firms is a local optimum price strategy if (i) for every $z \in I_{A}$ and for every small deviation of the price $\underline{p}_{A}^{z}$, the ex-ante profit $\pi_{A}^{E A}(z)$ of firm $A$ decreases, and for every $w \in I_{B}$ and for every small deviation of the price $\underline{p}_{B}^{w}$, the ex-ante profit $\pi_{B}^{E A}(w)$ of firm $B$ decreases (local optimum property); and (ii) for every $z \in I_{A}$ and $w \in I_{B}$, the indifferent consumer exists, i.e. $0<\underline{x}^{z, w}<l$ (duopoly property).

We introduce the BUC condition that has the crucial economical information that can be extracted from the exogenous variables. The BUC condition allows us to know if there is, or not, a local optimum price strategy in the presence of uncertainty for the production costs of both firms.

Definition 4.2 The Hotelling model satisfies the bounded uncertain costs (BUC) condition, if

$$
\left|3 \Delta_{C}-\Delta_{E}\right|<6 t l,
$$

for all $z \in I_{A}$ and for all $w \in I_{B}$.

The following theorem is a key economical result in oligopoly theory. First, it tell us about the existence, or not, of a local optimum price strategy only by accessing a simple inequality in the exogenous variables and so available to both firms. Secondly, gives us explicit and simple formulas that allow the firms to know the relevance of the exogenous variables in their price strategies and corresponding profits.

THEOREM 4.3 There is a local optimum price strategy $\left(\underline{p}_{A}, \underline{p}_{B}\right)$ if and only if the BUC condition holds. Under the BUC condition, the expected prices of the local optimum price strategy are given by 


$$
\begin{aligned}
& E\left(\underline{p}_{A}\right)=t l+E\left(c_{A}\right)-\frac{\Delta_{E}}{3} ; \\
& E\left(\underline{p}_{B}\right)=t l+E\left(c_{B}\right)+\frac{\Delta_{E}}{3} .
\end{aligned}
$$

Furthermore, the local optimum price strategy $\left(\underline{p}_{A}, \underline{p}_{B}\right)$ is unique and it is given by

$$
\underline{p}_{A}^{z}=E\left(\underline{p}_{A}\right)+\frac{\Delta_{A}}{2} ; \quad \underline{p}_{B}^{w}=E\left(\underline{p}_{B}\right)+\frac{\Delta_{B}}{2} .
$$

We note that for different production costs, the differences between the optimal prices of a firm are proportional to the differences of the production costs

$$
\underline{p}_{A}^{z_{1}}-\underline{p}_{A}^{z_{2}}=\frac{c_{A}^{z_{1}}-c_{A}^{z_{2}}}{2} .
$$

and

$$
\underline{p}_{B}^{w_{1}}-\underline{p}_{B}^{w_{2}}=\frac{c_{B}^{w_{1}}-c_{B}^{w_{2}}}{2} .
$$

for all $z_{1}, z_{2} \in I_{A}$ and $w_{1}, w_{2} \in I_{B}$. Hence, half of the production costs value is incorporated in the price.

Let $\alpha_{A}$ and $\alpha_{B}$ be given by

$$
\alpha_{A}=\max \left\{E\left(c_{B}\right)-c_{B}^{w}: w \in I_{B}\right\} \text { and } \alpha_{B}=\max \left\{E\left(c_{A}\right)-c_{A}^{z}: z \in I_{A}\right\} .
$$

The following corollary give us the information of the market size of both firms by giving the explicit localization of the indifferent consumer with respect to the local optimum price strategy.

COROllary 4.4 Under the BUC condition, the indifferent consumer $x^{z, w}$ is given by

$$
\underline{x}^{z, w}=\frac{l}{2}+\frac{\Delta_{E}-3 \Delta_{C}}{12 t} .
$$

The pair of prices $\left(\underline{p}_{A}, \underline{p}_{B}\right)$ satisfies

$$
\underline{p}_{A}^{z}-c_{A}^{z} \geq \alpha_{A} / 2 ; \quad \underline{p}_{B}^{w}-c_{B}^{w} \geq \alpha_{B} / 2 .
$$

Proof (of Theorem 4.3 and Corollary 4.4) Under incomplete information, each firm seeks to maximize its ex-ante profit. From (11), the ex-ante profit for firm $A$ is given by

$$
\begin{aligned}
\pi_{A}^{E A}\left(c_{A}^{z}\right) & =\int_{I_{B}}\left(p_{A}^{z}-c_{A}^{z}\right)\left(\frac{p_{B}^{w}-p_{A}^{z}+t l}{2 t}\right) \mathrm{d} q_{B}(w) \\
& =\left(p_{A}^{z}-c_{A}^{z}\right)\left(\frac{E\left(p_{B}\right)-p_{A}^{z}+t l}{2 t}\right) .
\end{aligned}
$$

From the first-order condition FOC applied to the ex-ante profit of firm $A$, we obtain

$$
p_{A}^{z}=\frac{c_{A}^{z}+E\left(p_{B}\right)+t l}{2} .
$$

Similarly,

$$
\pi_{B}^{E A}\left(c_{B}^{w}\right)=\left(p_{B}^{w}-c_{B}^{w}\right)\left(\frac{E\left(p_{A}\right)-p_{B}^{w}+t l}{2 t}\right)
$$


and, by the FOC, we obtain

$$
p_{B}^{w}=\frac{c_{B}^{w}+E\left(p_{A}\right)+t l}{2} .
$$

Then, from (18) and (20),

$$
\begin{aligned}
& E\left(p_{A}\right)=\frac{E\left(c_{A}\right)+E\left(p_{B}\right)+t l}{2} ; \\
& E\left(p_{B}\right)=\frac{E\left(c_{B}\right)+E\left(p_{A}\right)+t l}{2} .
\end{aligned}
$$

Solving the system of two equations, we obtain that

$$
\begin{aligned}
& E\left(p_{A}\right)=t l+\frac{E\left(c_{B}\right)+2 E\left(c_{A}\right)}{3} ; \\
& E\left(p_{B}\right)=t l+\frac{E\left(c_{A}\right)+2 E\left(c_{B}\right)}{3} .
\end{aligned}
$$

Hence, equalities (12) and (13) are satisfied. Replacing (13) in (18) and replacing (12) in (20), we obtain that

$$
\begin{aligned}
& p_{A}^{z}=t l+\frac{c_{A}^{z}}{2}+\frac{1}{6}\left(E\left(c_{A}\right)+2 E\left(c_{B}\right)\right) ; \\
& p_{B}^{w}=t l+\frac{c_{B}^{w}}{2}+\frac{1}{6}\left(2 E\left(c_{A}\right)+E\left(c_{B}\right)\right) .
\end{aligned}
$$

Hence, Equation (14) is satisfied.

Replacing in Equation (10) the values of $\underline{p}_{A}$ and $\underline{p}_{B}$ given by the Equation (14), we obtain that the indifferent consumer $x^{z, w}$ is given by

$$
x^{z, w}=\frac{l}{2}+\frac{3\left(c_{B}^{w}-c_{A}^{z}\right)+E\left(c_{A}\right)-E\left(c_{B}\right)}{12 t} .
$$

Hence, Equation (15) is satisfied. Therefore, $\left(\underline{p}_{A}, \underline{p}_{B}\right)$ satisfies property (ii) if and only if the BUC condition holds.

Since the ex-ante profit functions (17) and (19) are concave, the second-order conditions for this maximization problem are satisfied and so the prices $\underline{p}_{A}^{z}$ and $\underline{p}_{B}^{w}$ are indeed maxima for the functions (17) and (19), respectively. Therefore, the pair $\left(\underline{p}_{A}^{z}, \underline{p}_{B}^{w}\right)$ satisfies property (i) and so $\left(\underline{p}_{A}^{z}, \underline{p}_{B}^{w}\right)$ is a local optimum price strategy.

Let us prove that $\underline{p}_{A}^{z}$ and $\underline{p}_{B}^{w}$ satisfy inequalities (16). By Equation (14),

$$
\begin{aligned}
& \underline{p}_{A}^{z}-c_{A}^{z}=t l-\frac{c_{A}^{z}}{2}+\frac{1}{6}\left(E\left(c_{A}\right)+2 E\left(c_{B}\right)\right) ; \\
& \underline{p}_{B}^{w}-c_{B}^{w}=t l-\frac{c_{B}^{w}}{2}+\frac{1}{6}\left(2 E\left(c_{A}\right)+E\left(c_{B}\right)\right) .
\end{aligned}
$$

By the BUC condition, for every $w \in I_{B}$, we obtain

$$
\begin{aligned}
6\left(\underline{p}_{A}^{z}-c_{A}^{z}-t l\right) & =-3 c_{A}^{z}+E\left(c_{A}\right)+2 E\left(c_{B}\right) \\
& =3\left(E\left(c_{B}\right)-c_{B}^{w}\right)-3\left(c_{A}^{z}-c_{B}^{w}\right)+E\left(c_{A}\right)-E\left(c_{B}\right) \\
& >3\left(E\left(c_{B}\right)-c_{B}^{w}\right)-6 t l .
\end{aligned}
$$


Similarly, by the BUC condition, for every $z \in I_{A}$, we obtain

$$
\begin{aligned}
6\left(\underline{p}_{B}^{w}-c_{B}^{w}-t l\right) & =-3 c_{B}^{w}+2 E\left(c_{A}\right)+E\left(c_{B}\right) \\
& =3\left(E\left(c_{A}\right)-c_{A}^{z}\right)-3\left(c_{B}^{w}-c_{A}^{z}\right)-E\left(c_{A}\right)+E\left(c_{B}\right) \\
& >3\left(E\left(c_{A}\right)-c_{A}^{z}\right)-6 t l .
\end{aligned}
$$

Hence, inequalities (16) are satisfied.

\section{Comparative profit analysis}

From now on, we assume that the BUC condition holds and that the price strategy $\left(\underline{p}_{A}, \underline{p}_{B}\right)$ is the local optimum price strategy determined in Theorem 4.3.

The ex-post profit of the firms is the effective profit of the firms given a realization of the production costs for both firm. Hence, it is the main economic information for both firms. By Equation (14), the ex-post profit of firm $A$ is

$$
\underline{\pi}_{A}^{E P}(z, w)=\frac{\left(6 t l+\Delta_{E}-3 \Delta_{C}\right)\left(6 t l+\Delta_{E}-3 \Delta_{C}-3 \Delta_{B}\right)}{72 t}
$$

and the ex-post profit of firm $B$ is

$$
\underline{\pi}_{B}^{E P}(z, w)=\frac{\left(6 t l-\Delta_{E}+3 \Delta_{C}\right)\left(6 t l-\Delta_{E}+3 \Delta_{C}-3 \Delta_{A}\right)}{72 t} .
$$

We observe that the differences between the ex-post profits of both firms has a very useful and clear economical interpretation in terms of the localization and expected cost deviations.

$$
\underline{\pi}_{A}^{E P}(z, w)-\underline{\pi}_{B}^{E P}(z, w)=\frac{6 t l\left(\Delta_{A}-\Delta_{B}\right)+\left(\Delta_{E}-3 \Delta_{C}\right)\left(8 t l-\Delta_{A}-\Delta_{B}\right)}{24 t}
$$

Furthermore, for different production costs, the differences between the ex-post profit of a firm is given by

$$
\underline{\pi}_{A}^{E P}\left(z_{1}, w\right)-\underline{\pi}_{A}^{E P}\left(z_{2}, w\right)=\frac{\left(c_{A}^{z_{2}}-c_{A}^{z_{1}}\right)\left(12 t l-\Delta_{E}+3\left(c_{B}^{w}+E\left(c_{A}\right)-c_{A}^{z_{1}}-c_{A}^{z_{2}}\right)\right)}{24 t}
$$

and

$\underline{\pi}_{B}^{E P}\left(z, w_{1}\right)-\underline{\pi}_{A}^{E P}\left(z, w_{2}\right)=\frac{\left(c_{B}^{w_{2}}-c_{B}^{w_{1}}\right)\left(12 t l+\Delta_{E}+3\left(c_{A}^{z}+E\left(c_{B}\right)-c_{B}^{w_{1}}-c_{B}^{w_{2}}\right)\right)}{24 t}$

for all $z, z_{1}, z_{2} \in I_{A}$ and $w, w_{1}, w_{2} \in I_{B}$.

The ex-ante profit of a firm is the expected profit of the firm that knows its production cost but is uncertain about the production costs of the competitor firm. Since

$$
\underline{\pi}_{A}^{E P}(z, w)=\frac{\left(6 t l+\Delta_{E}+3\left(c_{B}^{w}-c_{A}^{z}\right)\right)\left(6 t l+\Delta_{E}+3\left(E\left(c_{B}\right)-c_{A}^{z}\right)\right)}{72 t},
$$

the ex-ante profit of firm $A$ is

$$
\begin{aligned}
\underline{\pi}_{A}^{E A}(z) & =\frac{\left(6 t l+\Delta_{E}+3\left(E\left(c_{B}\right)-c_{A}^{z}\right)\right)\left(6 t l+\Delta_{E}+3\left(E\left(c_{B}\right)-c_{A}^{z}\right)\right)}{72 t} \\
& =\frac{\left(6 t l-3 \Delta_{A}-2 \Delta_{E}\right)^{2}}{72 t} .
\end{aligned}
$$


Similarly, the ex-ante profit of firm $B$ is

$$
\underline{\pi}_{B}^{E A}(w)=\frac{\left(6 t l-3 \Delta_{B}+2 \Delta_{E}\right)^{2}}{72 t} .
$$

We observe that the differences between the ex-ante profits of both firms has a very useful and clear economical interpretation in terms of the localization and expected cost deviations.

$$
\underline{\pi}_{A}^{E A}(z)-\underline{\pi}_{B}^{E A}(w)=\frac{\left(4 t l-\Delta_{A}-\Delta_{B}\right)\left(3\left(\Delta_{B}-\Delta_{A}\right)-4 \Delta_{E}\right)}{24 t}
$$

Furthermore, for different production costs, the differences between the ex-ante profits of a firm are given by

$$
\underline{\pi}_{A}^{E A}\left(z_{1}\right)-\underline{\pi}_{A}^{E A}\left(z_{2}\right)=\frac{\left(c_{A}^{z_{2}}-c_{A}^{z_{1}}\right)\left(3\left(4 t l+2 E\left(c_{A}\right)-c_{A}^{z_{1}}-c_{A}^{z_{2}}\right)-4 \Delta_{E}\right)}{24 t}
$$

and

$$
\underline{\pi}_{B}^{E A}\left(w_{1}\right)-\underline{\pi}_{A}^{E A}\left(w_{2}\right)=\frac{\left(c_{B}^{w_{2}}-c_{B}^{w_{1}}\right)\left(3\left(4 t l+2 E\left(c_{B}\right)-c_{B}^{w_{1}}-c_{B}^{w_{2}}\right)+4 \Delta_{E}\right)}{24 t}
$$

for all $z, z_{1}, z_{2} \in I_{A}$ and $w, w_{1}, w_{2} \in I_{B}$.

The difference between the ex-post and the ex-ante profit for a firm is the real deviation from the realized gain of the firm and the expected gain of the firm knowing its own production cost but being uncertain about the production cost of the other firm. It is the best measure of the risk involved for the firm given the uncertainty in the production costs of the other firm. The difference between the ex-post profit and the ex-ante profit for firm $A$ is

$$
\underline{\pi}_{A}^{E P}(z, w)-\underline{\pi}_{A}^{E A}(z)=\frac{\Delta_{B}}{24 t}\left(6 t l-2 \Delta_{E}-3 \Delta_{A}\right) .
$$

The difference between the ex-post profit and the ex-ante profit for firm $B$ is

$$
\underline{\pi}_{B}^{E P}(z, w)-\underline{\pi}_{B}^{E A}(w)=\frac{\Delta_{A}}{24 t}\left(6 t l+2 \Delta_{E}-3 \Delta_{B}\right) .
$$

Definition 5.1 The Hotelling model satisfies the A-bounded uncertain costs (A-BUC) condition, if for all $z \in I_{A}$

$$
\left|3 \Delta_{A}+2 \Delta_{E}\right|<6 t l .
$$

The Hotelling model satisfies the $B$-bounded uncertain costs $(B-B U C)$ condition, if for all $w \in I_{B}$

$$
\left|3 \Delta_{B}-2 \Delta_{E}\right|<6 t l \text {. }
$$

The following corollary tells us that the sign of the risk of a firm has the opposite sign of the deviation of the competitor firm realized production cost from its average. Hence, under incomplete information the sign of the risk of a firm is not accessible to the firm. However, the probability of the sign of the risk of a firm to be positive or negative is accessible to the firm.

Corollary 5.2 Under the A-bounded uncertain costs (A-BUC) condition,

$$
\underline{\pi}_{A}^{E P}(z, w)<\underline{\pi}_{A}^{E A}(z) \text { if and only if } \Delta_{B}<0 .
$$


Under the B-bounded uncertain costs $(B-B U C)$ condition,

$$
\underline{\pi}_{B}^{E P}(z, w)<\underline{\pi}_{B}^{E A}(w) \text { if and only if } \Delta_{A}<0 .
$$

The proof of the above corollary follows from a simple manipulation of the previous formulas for the ex-post and ex-ante profits.

The expected profit of the firm is the expected gain of the firm. We observe that the ex-ante and the ex-posts profits of both firms are strictly positive with respect to the local optimum price strategy. Hence, the expected profits of both firms are also strictly positive. Since the ex-ante profit $\underline{\pi}_{A}^{E A}(z)$ of firm $A$ is equal to

$$
\underline{\pi}_{A}^{E A}(z)=\frac{9 \Delta_{A}^{2}-12 \Delta_{A}\left(3 t l-\Delta_{E}\right)+4\left(3 t l-\Delta_{E}\right)^{2}}{72 t},
$$

from (8), we obtain that the expected profit of firm $A$ is given by

$$
E\left(\underline{\pi}_{A}^{E P}\right)=\frac{\left(3 t l-\Delta_{E}\right)^{2}}{18 t}+\frac{V_{A}}{8 t}
$$

Similarly, the expected profit of firm $B$ is given by

$$
E\left(\underline{\pi}_{B}^{E P}\right)=\frac{\left(3 t l+\Delta_{E}\right)^{2}}{18 t}+\frac{V_{B}}{8 t} .
$$

The difference between the ex-ante and the expected profit of a firm is the deviation from the expected realized gain of the firm given the realization of its own production cost and the expected gain in average for different realizations of its own production cost, but being in both cases uncertain about the production costs of the competitor firm. It is the best measure of the quality of its realized production cost in terms of the expected profit over its own production costs.

COROLlary 5.3 The difference between the ex-ante profit and the expected profit for firm A is

$$
E\left(\underline{\pi}_{A}^{E P}\right)-\underline{\pi}_{A}^{E A}(z)=\frac{\left(12 t l-3 \Delta_{A}-4 \Delta_{E}\right) \Delta_{A}+3 V_{A}}{24 t}
$$

The difference between the ex-ante profit and the expected profit for firm $B$ is

$$
E\left(\underline{\pi}_{B}^{E P}\right)-\underline{\pi}_{B}^{E A}(w)=\frac{\Delta_{B}\left(12 t l-3 \Delta_{B}+4 \Delta_{E}\right)+3 V_{B}}{24 t} .
$$

Proof Let $X=3 t l-\Delta_{E}$. Hence,

$$
\begin{aligned}
\underline{\pi}_{A}^{E A}(z)-E\left(\underline{\pi}_{A}^{E P}\right) & =\frac{\left(2 X-3 \Delta_{A}\right)^{2}-4 X^{2}-9 V_{A}}{72 t} \\
& =\frac{\left(3 \Delta_{A}-4 X\right) \Delta_{A}-3 V_{A}}{24 t}
\end{aligned}
$$

and so equality (23) holds. The proof of equality (24) follows similarly. 


\section{Comparative consumer surplus and welfare analysis}

The ex-post consumer surplus is the realized gain of the consumers community for given outcomes of the production costs of both firms. Under incomplete information, by Equation (4), the ex-post consumer surplus is

$$
\underline{C S}^{E P}=v_{T} l-\frac{3}{2} t l^{2}-\frac{l}{3}\left(2 E\left(c_{B}\right)+E\left(c_{A}\right)\right)-\frac{\Delta_{B} l}{2}+\frac{\left(6 t l-3 \Delta_{C}+\Delta_{E}\right)^{2}}{144 t} .
$$

The expected value of the consumer surplus is the expected gain of the consumers community for all possible outcomes of the production costs of both firms. The expected value of the consumer surplus $E\left(\underline{C S}^{E P}\right)$ is given by

$$
\begin{aligned}
E\left(\underline{C S}^{E P}\right) & =\int_{I_{B}} \int_{I_{A}} \underline{C S}^{E P} \mathrm{~d} q_{A}(z) \mathrm{d} q_{B}(w) \\
& =v_{T} l-\frac{3}{2} t l^{2}-\frac{l}{3}\left(2 E\left(c_{B}\right)+E\left(c_{A}\right)\right)+U_{1}
\end{aligned}
$$

where

$$
U_{1}=\frac{\left(6 t l+\Delta_{E}\right)^{2}-6 E\left(\Delta_{C}\right)\left(6 t l+\Delta_{E}\right)+9 E\left(\Delta_{C}^{2}\right)}{144 t} .
$$

From equality (9), we obtain that

$$
\begin{aligned}
U_{1} & =\frac{\left(6 t l+\Delta_{E}\right)^{2}-6 \Delta_{E}\left(6 t l+\Delta_{E}\right)+9\left(V_{A}+V_{B}+\Delta_{E}^{2}\right)}{144 t} \\
& =\frac{\left(6 t l-2 \Delta_{E}\right)^{2}+9\left(V_{A}+V_{B}\right)}{144 t} .
\end{aligned}
$$

Hence,

$$
E\left(\underline{C S}^{E P}\right)=v_{T} l-\frac{3}{2} t l^{2}-\frac{l}{3}\left(2 E\left(c_{B}\right)+E\left(c_{A}\right)\right)+\frac{\left(6 t l-2 \Delta_{E}\right)^{2}+9\left(V_{A}+V_{B}\right)}{144 t} .
$$

The difference between the ex-post consumer surplus and the expected value of the consumer surplus measures the difference between the gain of the consumers for the realized outcomes of the production costs of both firms and the expected gain of the consumers for all possible outcomes of the production costs of both firms. Hence, the risk taken by the consumers for different outcomes of the production costs of both firms is measured.

COROllary 6.1 The difference between the ex-post consumer surplus and the expected value of the consumer surplus is

$$
\underline{C S}^{E P}-E\left(\underline{C S}^{E P}\right)=-\frac{\Delta_{A}+\Delta_{B}}{4} l+\frac{\left(\Delta_{E}-3 \Delta_{C}\right)^{2}-4 \Delta_{E}^{2}-9\left(V_{A}+V_{B}\right)}{144 t} .
$$


Proof

$$
\begin{aligned}
\underline{C S}^{E P}-E\left(\underline{C S}^{E P}\right) \\
=-\frac{\Delta_{B} l}{2}+\frac{\left(6 t l-3 \Delta_{C}+\Delta_{E}\right)^{2}-\left(6 t l-2 \Delta_{E}\right)^{2}-9\left(V_{A}+V_{B}\right)}{144 t} \\
=-\frac{\Delta_{B} l}{2}+\frac{36 t l\left(\Delta_{E}-\Delta_{C}\right)+\left(\Delta_{E}-3 \Delta_{C}\right)^{2}-4 \Delta_{E}^{2}-9\left(V_{A}+V_{B}\right)}{144 t} \\
=\frac{\Delta_{E}-\Delta_{C}-2 \Delta_{B}}{4} l+\frac{\left(\Delta_{E}-3 \Delta_{C}\right)^{2}-4 \Delta_{E}^{2}-9\left(V_{A}+V_{B}\right)}{144 t} \\
=-\frac{\Delta_{A}+\Delta_{B}}{4} l+\frac{\left(\Delta_{E}-3 \Delta_{C}\right)^{2}-4 \Delta_{E}^{2}-9\left(V_{A}+V_{B}\right)}{144 t} .
\end{aligned}
$$

The ex-post welfare is the realized gain of the state that includes the gains of the consumers community and the gains of the firms for a given outcomes of the production costs of both firms. By Equation (5), the ex-post welfare is

$$
\underline{W}^{E P}=v_{T} l-\frac{1}{4} t l^{2}-\frac{E\left(c_{A}\right)+E\left(c_{B}\right)+\Delta_{A}+\Delta_{B}}{2} l-\frac{3 \Delta_{C}\left(2 \Delta_{E}-9 \Delta_{C}\right)+\left(\Delta_{E}\right)^{2}}{144 t} .
$$

The expected value of the welfare is the expected gain of the state for all possible outcomes of the production costs of both firms. The expected value of the welfare $E\left(\underline{W}^{E P}\right)$ is given by

$$
\begin{aligned}
E\left(\underline{W}^{E P}\right) & =\int_{I_{B}} \int_{I_{A}} \underline{W}^{E P} \mathrm{~d} q_{A}(z) \mathrm{d} q_{B}(w) \\
& =v_{T} l-\frac{1}{4} t l^{2}-\frac{E\left(c_{A}\right)+E\left(c_{B}\right)}{2} l+U_{2}
\end{aligned}
$$

where

From equality (9), we obtain that

$$
U_{2}=\frac{27 E\left(\Delta_{C}^{2}\right)-6 E\left(\Delta_{C}\right) \Delta_{E}-\Delta_{E}^{2}}{144 t}
$$

$$
U_{2}=\frac{27\left(V_{A}+V_{B}+\Delta_{E}^{2}\right)-6 \Delta_{E}^{2}-\Delta_{E}^{2}}{144 t}=\frac{27\left(V_{A}+V_{B}\right)+20 \Delta_{E}^{2}}{144 t} .
$$

Hence,

$$
E\left(\underline{W}^{E P}\right)=v_{T} l-\frac{1}{4} t l^{2}-\frac{E\left(c_{A}\right)+E\left(c_{B}\right)}{2} l+\frac{27\left(V_{A}+V_{B}\right)+20 \Delta_{E}^{2}}{144 t} .
$$

The difference between the ex-post welfare and the expected value of the welfare measures the difference in the gains of the state between the realized outcomes of the production costs of both firms and the expected gain of the state for all possible outcomes of the production costs of both firms. Hence, the risk taken by the state for different outcomes of the production costs of both firms is measured. The difference between the ex-post welfare and the expected value of welfare is

$$
\underline{W}^{E P}-E\left(\underline{W}^{E P}\right)=-\frac{\Delta_{A}+\Delta_{B}}{2} l+\frac{9\left(\Delta_{C}^{2}-V_{A}-V_{B}\right)-2 \Delta_{C} \Delta_{E}-7 \Delta_{E}^{2}}{48 t} .
$$




\section{Example: symmetric Hotelling}

A Hotelling game is symmetric, if $\left(I_{A}, \Omega_{A}, q_{A}\right)=\left(I_{B}, \Omega_{B}, q_{B}\right)$ and $c=c_{A}=c_{B}$. Hence, we observe that all the formulas of this paper hold with the following simplifications

$$
\Delta_{E}=0 ; \quad E(c)=E\left(c_{A}\right)=E\left(c_{B}\right) \text { and } V=V_{A}=V_{B} .
$$

The bounded uncertain costs in the symmetric case can be written in the following simple way.

Definition 7.1 The Hotelling model satisfies the BUC condition, if

$$
\left|\Delta_{C}\right|<2 t l
$$

for all $z \in I_{A}$ and for all $w \in I_{B}$.

Under the BUC condition, the expected prices of the local optimum price strategy have the simple expression

$$
E\left(\underline{p}_{A}\right)=E\left(\underline{p}_{B}\right)=t l+E(c) .
$$

We observe that that the A-BUC and B-BUC conditions are implied by the BUC condition. Hence, Corollary 5.2 can be rewritten without any restriction, i.e.

$$
\underline{\pi}_{A}^{E P}(z, w)<\underline{\pi}_{A}^{E A}(z) \quad \text { if and only if } \quad \Delta_{B}<0
$$

and

$$
\underline{\pi}_{B}^{E P}(z, w)<\underline{\pi}_{B}^{E A}(w) \text { if and only if } \quad \Delta_{A}<0 .
$$

Furthermore, the difference between the ex-post welfare and the expected value of welfare has the simple expression

$$
\underline{W}^{E P}-E\left(\underline{W}^{E P}\right)=-\frac{\Delta_{A}+\Delta_{B}}{2} l+\frac{3\left(\Delta_{C}^{2}-2 V\right)}{16 t} .
$$

Hence, $\underline{W}^{E P}>E\left(\underline{W}^{E P}\right)$ if and only if

$$
6 V<3 \Delta_{C}^{2}-8 \operatorname{tl}\left(\Delta_{A}+\Delta_{B}\right) .
$$

\section{Conclusion}

We introduced a new condition on the exogenous variables that we called the BUC condition. We proved that there is a local optimum price strategy if and only if the BUC condition is satisfied. We gave the explicit formula for the local optimum price strategy and we observe that the formula does not depend on the distributions of the production costs of the firms, except on their first moments. Furthermore, the local optimum price strategy determine prices for both firms that are affine with respect to the expected costs of both firms and to its own costs. The corresponding expected profits are quadratic in the expected cost of both firms, in its own cost and in the transportation cost. We did the ex-ante versus ex-post analysis of the profits. We proved that, under the A-BUC and B-BUC conditions, the expost profit of a firm is smaller than its ex-ante profit if and only if the production cost of the competitor firm is greater than its expected cost. Then, we proved that the A-BUC and $\mathrm{B}-\mathrm{BUC}$ conditions are implied by the BUC condition, if the distribution of the production 
costs of both firms coincide (symmetric Hotelling). Further, research work can consist (i) in finding sufficient and necessary conditions for the local optimum price strategy to be a Nash equilibrium; (ii) to solve the localization problem by studying the cases where the firms are not located at the ends of the segment line; (iii) to extend the result to quadratic transportation costs; and (iv) to extend the result to networks.

\section{Acknowledgements}

We are thankful to the anonymous referees for their suggestions. We acknowledge the financial support of LIAAD-INESC TEC through Strategic Project-LA 14-2013-2014 with reference PEstC/EEI/LA0014/2013, USP-UP project, IJUP, Faculty of Sciences, University of Porto, Calouste Gulbenkian Foundation, FEDER, POCI 2010 and COMPETE Programmes and Fundação para a Ciência e a Tecnologia (FCT) through Project Dynamics and Applications, with reference PTDC/ MAT/121107/2010. Telmo Parreira thanks FCT for the PhD scholarship SFRH/BD/33762/2009.

\section{References}

[1] Hotelling H. Stability in competition. Econ. J. 1929;39:41-57.

[2] Graitson D. Spatial competition la Hotelling: a selective survey. J. Indus. Econ. 1982;31:11-25.

[3] Osborne MJ, Pitchick C. Equilibrium in Hotelling's model of spatial competition. Econometrica. 1987;55:911-922.

[4] Pinto AA, Parreira T. A Hotelling-type network. In: Peixoto M, Pinto AA, Rand D, editors. Dynamics, games and science I. Vol. 1, Springer proceedings in mathematics. Berlin: SpringerVerlag; 2011. p. 709-720.

[5] Pinto AA, Parreira T. Optimal localization of firms in Hotelling networks. In: Pinto AA, Zilberman D, editors. Modeling, dynamics, optimization and bioeconomy. Vol. 73, Springer proceedings in mathematics and statistics. Berlin: Springer-Verlag; 2014.

[6] Pinto AA, Parreira T. Complete versus incomplete information in the Hotelling model. In: Pinto AA, Zilberman D, editors. Modeling, dynamics, optimization and bioeconomy. Vol. 73, Springer proceedings in mathematics and statistics. Berlin: Springer-Verlag; 2014.

[7] Pinto AA, Parreira T. Maximal differentiation in the Hotelling model with uncertainty. In: Pinto AA, Zilberman D, editors. Modeling, dynamics, optimization and bioeconomy. Vol. 73, Springer proceedings in mathematics and statistics. Berlin: Springer-Verlag; 2014.

[8] Salop S. Monopolistic competition with outside goods. Bell J. Econ. 1979;10:141-156.

[9] Tabuchi T, Thisse JF. Asymmetric equilibria in spatial competition. Int. J. Econ. Theory. 1995;13:213-227.

[10] D'Aspremont C, Gabszewicz J, Thisse J-F. On Hotelling's "stability in competition". Econometrica. 1979;47:1145-1150.

[11] Ziss S. Entry deterrence, cost advantage and horizontal product differentiation. Regional Sci. Urban Econ. 1993;23:523-543.

[12] Boyer M, Laffont J, Mahenc P, Moreaux M. Location distortions under incomplete information. Regional Sci. Urban Econ. 1994;24:409-440.

[13] Lederer P, Hurter A. Competition of firms: discriminatory pricing and location. Econometrica. 1986;54:623-640.

[14] Boyer M, Mahenc P, Moreaux M. Asymmetric information and product differentiation. Regional Sci. Urban Econ. 2003a;33:93-113.

[15] Biscaia R, Sarmento P. Spatial competition and firms' location decisions under cost uncertainty. FEP Working Papers n445; 2012. 
[16] Ferreira F, Ferreira FA, Ferreira M, Pinto AA. Flexibility in a Stackelberg leadership with differentiated goods. Optimization. Forthcoming. doi:10.1080/02331934.2013.836649.

[17] Ferreira F, Ferreira FA, Pinto AA. Price-setting dynamical duopoly with incomplete information. In: Machado JA, Silva MF, Barbosa RS, Figueiredo LB, editors. Nonlinear science and complexity. Dordrecht: Springer; 2011. p. 397-404.

[18] Ferreira F, Ferreira FA, Pinto AA. Flexibility in Stackelberg leadership. In: Machado JA, Patkai $\mathrm{B}$, Rudas IJ, editors. Intelligent engineering systems and computational cybernetics. Netherlands: Springer; 2009. p. 399-405.

[19] Ferreira F, Ferreira FA, Pinto AA. Bayesian price leadership. In: Tas K, Tenreiro Machado JA, Baleanu D, editors. Mathematical methods in engineering. Dordrecht: Springer; 2007. p. 371-379.

[20] Ferreira FA, Ferreira F, Pinto AA. Unknown costs in a duopoly with differentiated products. In: Tas K, Tenreiro Machado JA, Baleanu D, editors. Mathematical methods in engineering. Dordrecht: Springer; 2007. p. 359-369.

[21] Ferreira M, Figueiredo IP, Oliveira BMPM, Pinto AA. Strategic optimization in R\&D investment. Optim. J. Math. Prog. Oper. Res. 2012;61:1013-1023.

[22] Ferreira FA, Pinto AA. Uncertainty on a Bertrand duopoly with product differentiation. In: Machado JA, Silva MF, Barbosa RS, Figueiredo LB, editors. Nonlinear science and complexity. Dordrecht: Springer; 2011. p. 389-395.

[23] Gibbons R. A primer in game theory. New York (NY): Financial Times Prentice Hall; 1992.

[24] Pinto AA, Ferreira FA, Ferreira M, Oliveira BMPM. Cournot duopoly with competition in the R\&D expenditures. Vol. 7, Proceedings of symposia in pure mathematics. Weinheim: WileyVCH Verlag; 2007.

[25] Pinto AA, Oliveira BMPM, Ferreira FA, Ferreira F. Stochasticity favoring the effects of the $R \& D$ strategies of the firms. In: Machado JA, Patkai B, Rudas IJ, editors. Intelligent engineering systems and computational cybernetics. Netherlands: Springer; 2008. p. 415-423. 